Volume 3 No. 2, Desember 2018

P ISSN 2442-594X | E ISSN 2579-5708

http://journal.iainlangsa.ac.id/index.php/tibyan

DOI: 10.32505/tibyan.v3i2.698

\title{
MENANGKAP PESAN TUHAN: URGENSI KONTEKSTUALISASI ALQURAN MELALUI HERMEUNETIKA
}

\author{
Capture The Lord's Message: Urgency Of The Qur'anic's Contextualization \\ Through Hermeneutics
}

\author{
Ismail Fahmi Arrauf Nasution \\ Institut Agama Islam Negeri Langsa \\ ismailfahmiarraufnasution@iainlangsa.ac.id \\ Miswari \\ Institut Agama Islam Negeri Langsa \\ miswari@iainlangsa.ac.id
}

\begin{abstract}
This article aims to explore hermeneutical thinking of contemporary Muslim thinkers. They are Fazlur Rahman, Nasir Hamid Abu Zayd, Mohammad Arkoun, Khaled Abou el-Fadl. These thinkers were greatly influenced by Western hermeneutical thinkers such as F. Sheiermacher, Wilhelm Dilthey, Martin Heidegger, Rydolf Bultmann, Hans-George Gadamer, Betti, Jurgen Habermas and Paul Ricoeur. The motivation of Muslim thinkers to use the hermeunetic approach developed by Western thinkers to reconstruct the meaning of the Qur'an was because they saw the initial motivation for the birth of hermeunetics from Western thinkers was because they wanted to reconstruct the Bible. The Qur'an and allegory are the same as the scriptures. The aspect that most influences Muslim thinkers in Western hermeunetic thinking towards the Qur'anic hermeneutics that they argue is the importance of reviewing the sociohistorical descent of the Qur'an in order to contextualize the Qur'an. Between humans and the Qur'an that has been made throughout history by various schools and religious authorities. With hermeneutics, the Qur'an wants to be returned to humanity as a powerful text for every situation, condition and age
\end{abstract}

Keywords: Hermeneutics, Qur'an, text, socio-historical, socio-cultural 


\begin{abstract}
Abstrak
Artikel ini bertujuan mengeksporasi pemikiran hermeunetika para pemikir muslim kontemporer. Mereka adalah Fazlur Rahman, Nasir Hamid Abu Zayd, Mohammad Arkoun, Khaled Abou el-Fadl. Para pemikir ini sangat dipengaruhi oleh para pemikir hermeunetika Barat seperti F. Sheiermacher, Wilhelm Dilthey, Martin Heidegger, Rydolf Bultmann,Hans-George Gadamer, Betti, Jurgen Habermas dan Paul Ricoeur. Motivasi para pemikir muslim untuk menggunakan pendekatan hermeunetika yang dikembangkan pemikir Barat untuk merekonstruksi pemaknaan Alquran adalah karena mereka melihat motivasi awal lahirnya hermeunetika dari para pemikir Barat itu adalah karena ingin merekonstruksi Alkitab. Alquran dan alkibat adalah sama-sama kitab suci.Aspek yang paling mempengaruhi pemikir Muslim dalam pemikiran hermeunetika Barat terhadap hermeunetika Alquran yang mereka gagas adalah pentingnya meninjau sosio-historis turunnya Alquran agar dapat mengkontekstalisasi Alquran.Kegunaan hermeunetika Alquran adalah untuk menghancurkan dindingdinding yang membatasi antara manusia dengan Alquran yang telah dibuat sepanjang sejarah oleh berbagai aliran dan otoritas agama.Dengan hermeunetika, Alquran ingin dikembalikan kepada umat manusia sebagai sebuat teks yang berdayaguna bagi setiap situasi, kondisi dan zaman.
\end{abstract}

Kata Kunci: Hermeunetika, Alquran, teks, sosio-historis, sosio-kultural

\title{
Pendahuluan
}

Islam adalah agamanya kaum Muslim yang berlandaskan pada keparcayaan pada Tuhan Yang Esa yang disampaikan melalui Nabi Muhammad sebagai utusan Allah ${ }^{1}$.The Contemporary English-Indonesia Dictonary menjelaskan beberapa kata turunan dari Islam yaitu: 'Islamic' yaitu hal-hal yang berhubungan dengan Islam, seperti 'Islamic festivals' yaitu festifal-festifal tentang Islam. 'Islamics' yaitu 'kegiatan mempelajari Islam. 'Islamism' yaitu 'agama Islam' 'Islamist' yaitu 'orang Islam ortodoks'².Islam bermakna penyerahan diri kepada kehendak Tuhan dan sebagai jalan menuju keselamatan ${ }^{3}$.

Muhammad lahir di Makkah pada 570 dan meninggal pada 632. Pada tahun kelahirannya, pasukan gajah dari Yaman dating ke Makkah untuk menghancurkan kabah $^{4}$.Kepada Nabi Muhammad diturunkan Alquran sebagai petunjuk bagi umat Manusia.Alquran ditujukan kepada umat manusia di semua zaman dan segala

\footnotetext{
${ }^{1}$ Joanna Florio and Dilys Parkinson, Oxford Advanced Learner Dictonary, (Oxford: Oxford University Press, 2000), h. 720.

${ }^{2}$ Peter Salim, The Contemporary English-Indonesia Dictonary, (Jakarta: Modern English Press, 1985), h. 1000.

${ }^{3}$ James Gardner, Encyclopedia of Faith and Religions of the World, Vol. III, (New Delhi: Aryan Books Inernational, 1999), h. 1177

${ }^{4}$ Mircea Eliade, The Encyclopedia of Religion, Vol. 9, (New York: Macmillan Library Reference USA, 1995), h. 137
} 
kondisi.Tetapi dewasa ini Alquran menjadi tidak dapat diterapkan pada segala konteks karena telah dibangun dinding besar yang menghalangi manusia dengan Alquran yaitu klaim-klam metafisis Alquran, hegemoni penarsiran oleh kelompok tertentu dan stigma bahwa Alquran tidak boleh diakses oleh sembarangan orang. Untuk menghancurkan dinding tersebut, para pemikir muslim kontemporer menyusun sebuah system untuk memahami Alquran dengan ilmu hermeunetika.

Penggunaan Hermeunetika dalam memahami Alquran dianggap sebagai tindakan terlarang oleh sebagian besar kalangan.Menutut mereka, Alquran itu tidak boleh didekati (aproaching) melalui hermeunetika karena kitab suci itu. Di Indonesia, resistensi hermeunetika dalam studi Alquran muncul dari kalangan INSIST Jakarta yang umumnya adalah anak-anak intelektual Syed Muhammad Naquib Al-Attasdi ISTAC Malaysia. Sementara itu, pihak-pihak yang sangat mendukung pendekatan hermeunetika Alquran adalah kalangan organisasi islam liberal, peneliti dan akademisi perguruan tinggi agama Islam di Indonesia ${ }^{5}$.

Sementara itu, kalangan yang mendukung hermeunetika berpendapat, urgensi hermeunetika muncul dari beberapa argumentasi seperti kesadaran bahwa kitab-kitab tafsir tidak mampu menghadirkan tawaran praktis terhadap persoalan-persoalan kontemporer, Alquran telah dianggap sebagai sebuah teks yang sangat sakral dan tidak bisa dilepaskan dari konteks kemunculannya sehingga pendayagunaannya tidak berorientasi kekinian melainkan selalu dikembalikan kepada kontek kemunculannya, bila tafsir hanya merupakan konsumsi elit agama maka hermeunetika mampu menangkap aspek relatif manusia sehingga dengan pendekatan hermeunetika, Alquran dapat memenuhi kebutuhan kontekstual setiap kalangan, hermeunetika mampu mendialogkan antara dunia pengarang, dunia teks dan dunia pembaca sehingga terhindar dari orientasi subjektif atas teks, meskipun hermeunetika merupakan istilah baru, tetapi praktik pendekatan ini telah lama dilakukan terhadap Alquran.

Sementara itu, penentang hermeunetika memiliki beberapa argumen mendasar dalam menolak hermeunetika Alquran.Pertama mereka meyakini bahwa tafsir telah dibangun dengan prinsip dan metode yang mampu meminimalisir kesalahan dan kesewenang-wenangan penafsir.Argumen kedua dalam penolakan tafsir adalah karena hermeunetika itu adalah ilmu dari Barat.Bagi mereka, ilmu itu bebas nilai. Kalau ilmu hermeunetika yang bebas nilai itu diterapkan sebagai pendekatan studi Alquran, maka pemahaman terhadap Alquran akan bebas nilai. Padahal Alquran diyakini memiliki nilai dan orientasi yang jelas.Ketiga adalah ketakutan-ketakutan tentang terjadinya dekonstruksi wahyu yang telah mapan, terjadinya perombakan dan anilir terhadap ketentuan hukum syariah dan posibilitas ilfiltrasi hukum Barat dan keempat dikhawatirkan terjadi prinsip buda relativitas Alquran. Alquran dikhawatirkan akan diinterpretasi sesukanya saja oleh berbagai pihak tanpa bekal keilmuan yang cukup. Sehingga terjadi kesesatan dalam memahami Alquran.

\footnotetext{
${ }^{5}$ Argumentasi penentangan hermeunetika untuk agama, lihat, Adian Husaini danAbdurrahman alBaghdadi, Hermeneutika \& Tafsir Al Quran, (Jakarta: Gema Isani Press, 2007), h. 12-15.
} 
Kekhawatiran terjadinya budaya hermeunetika Alquran muncul dari kalangan tradisional dan literalis.Meskipun berbeda, kedua kelompok ini sepakat bahwa hermeunetika Alquran berbahaya bagi pemahaman atas Alquran. Kalangan tadisional menolak hermeunetika karena selain tafsir dan komentar otoritatif terhadap agama tidak boleh menerapkan hermeunetika Alquran karena pelakunya diyakini tidak memiliki bekal yang cukup untuk menelaah Alquran secara langsung.Bahkan bagi kalangan tradisional, sebuah kitab yang merupakan produk penjelas dari ulama yang memiliki silsilah keilmuan yang jelas (mu'tabar) sementara itu kelompok literalis yang moderat menolak hermeunetika karena menurut mereka, Alquran dapat ditelaah langsung tanpa perlu bantuan ilmu-ilmu lain termasuk hermeunetika.Menurut mereka, Alquran dapat dikontekstualisasi langsung untuk merespon problematikan sosial tanpa perlu bantuan ilmu-ilmu tentang akses teks seperti hermeunetika dan tafsir ${ }^{6}$.

Sementara itu, kelompok sekular atau liberal adalah pejuang hermeunetika Alquran yang gigih.Mereka melihat hermeunetika adalah jawaban atas kemandegan kontekstualisasi Alquran dan akses langsung Alquran tanpa bantuan ilmu teks yang membuat ayat dan realitas menjadi tidak singkron sehingga problem-problem sosial menjadi tidak teratasi.Gagasan-gagasan sekularis banyak diinspirasi oleh pemikiran cemerlang dari Fazlur Rahman, Nasir Hamid Abu Zayd, Mohammad Arkoun, Khaled Abou el-Fadl.

Dilema ilmu teks adalah kemustahilan memposisikan diri pada posisi pengarang. Nietzsche meyakini bahwa pendekatan teks pasti bersifat perspektivis ${ }^{7}$.Sehingga bila dikaitkan dengan ilmu tafsir, maka kitab-kitab tafsir juga merupakan karya yang tidak bisa melepaskan pengarngnya dari perspektif tertentu khususnya mazhab yang dia anut.Keterkaitan penafsir Alquran (mufassir) dengan perspektifnya membuat Alquran menjadi semakin sulit dikonterkstualisasikan.Tafsir tidak mampu merepresentasikan Alquran sehingga dapat dikatakan antirepresentasi.

Gadamer telah menjelaskan bahwa pembaca tidak dapat memposisikan dirinya dalam posisi pengarang.Dengan demikian tafsir adalah sebau fusi horizan yang merupakan perpaduan horizon Tuhan dan horizon mufassir.Tradisi, baik itu mazhab yang diyakini, aliran teologi yang dianut, kapasitas penguasaan ilmu tafsir, lingkungan, konteks sosial, budaya mufassir sangat menentukan karya tafsir. Dengan demikian sebuah tafsir yang definitif, objektif dan univokal itu mustahil. Karena tafsir adalah sebuah kemustahilan, bahkan sebuah paradoks, maka hermeunetika adalah sebuah alternatif untuk memahami Alquran.

Bila tafsir arahnya sudah jelas yakni orientasi tradisi mufassir, maka hermeunetika sejak awal sudah terbuka bahwa kehadirannya adalah untuk mempertajam sesitivitas tentang adanya perbedaan pespektif. Dari keragaman pespektif inilah muncul kreativitas dan aneka alternatif kontekstualisasi Alquran dalam merespon problematika mutakhir.

\footnotetext{
${ }^{6}$ Henri Shalahuddin, Al-Qur'an Dihujat, Cet. II(Jakarta: Al-Qalam, 2007), h. 95.

${ }^{7}$ Akhyar Yusuf Lubis, Dekonstruksi Epistemologi Modern, (Jakarta: Pustaka Indonesia Satu, 2006), h. 241 .
} 
Telah banyak kajian tentang hermeunetika Alquran . Slamet Muliono R meneliti tentang filosofi dasar hermeunetika tentang penafsiran Alquran ${ }^{8}$. Aksin Wijaya meneliti tentang konversi orientasi Alquran dari orientasi ketuhanan menuju orientasi humanism melalui pendekatan hermeunetika'. Mokhamad Sukron menawarkan hermeunetika sebagai alternatif tafsir Alquran $^{10}$. Artikel ini berusaha menunjukkan hermeunetika Alquran yang di gagas para pemikir Muslim adalah gagasan-gagasan yang dipengaruhi oleh pemikir hermeunetika Barat.

\section{Hermeunetika Barat}

\section{Scheiermcher, Dilthey dan Heideggar}

Sekalipun Hermeunetika sebagai ilmu tetang pemaknaan teks telah memiliki akar yang jauh sebelum filsafat Yunani dan telah disinggunh oleh para filosof Yunani seperti Plato dan Aristoteles, tetapi ilmu tersebut baru mendapatkan fokusnya di tangan para pemikir modern seperti F. Sheiermacher (1768-1634), Wilhelm Dilthey (1833-1911), Martin Heidegger (1889-1979), Rydolf Bultmann (1884-1976), George Gadamer (1960), Betti (1962), Jurgen Habermas (1968), Paul Ricoeur (1969), Szondi (1975) dan Apel 1979). Scheiermacher adalah peletak dasar hermeunetika modern.Karena ayahnya adalah seorang pendeta, maka Scheiermacher sangat dekat dengan teks-teks Alkitab.Tetapi dia mengajukan berbagai pertanyaan-pertanyaan kritis terhadap teks-teks yang dianggapnya kurang rasional ${ }^{11}$.

Scheiermcher melihat, bila doktrin-doktrin irrasional masih terus diyakini dalam sistem keimanan Kristenn maka agama tersebut akan ditinggalkan. Berkat pengaruh perkembangan ilmu pengetahuan yang sangat pesat, doktrin-doktrin Gereja akan kehilangan tempatnya. Scheiermcher menegaskan bahwa teks-teks Injil itu ditulis oleh teolog pada zamannya.Injil adalah aktualisasi semangat zamannya.Untuk memahami Injil secara tepat, Scheiermcher menekankan pentingnya menyelami maksud pengarang.Dia yakin bahwa pembaca mampu memahami maksud pengarangarang. Pembaca memiliki potensi yang sama, berasal dari bumi yang sama dengan pengarang. Pembaca pasti mampu menyesuaikan diri dengan pengarang.

Kesadaran historitas Scheiermcher ini memperngaruhi para pemikir Muslim dalam merumuskan pemikiran hermeunetiknya tentang Alquran.Mereka menekankan kesadaran untuk menjadikan analisa historis Alquran sebagai salah satu penentu pemahaman dan kontekstualisasi Alquran.Tetapi adalah Dilthey yang menguatkan analisa sejarah dalamm studi Hermeunetika yang telah digagasa Scheiermcher ${ }^{12}$.

\footnotetext{
${ }^{8}$ Slamet Muliono R., "Hermeneutika Al-Qur'an: Antara Pemaknaan Tekstual Dan Kontekstual" Ulumuna, Volume XIV Nomor 1, 2010.

${ }^{9}$ Aksin Wijaya," Hermeneutika Al-Qur'an: Memburu Pesan Manusiawi Dalam Al-Qur'an”, Ulumuna, Volume XV Nomor 2 Desember 2011.

${ }^{10}$ Mokhamad Sukron ,'Kajian Hermeneutika Dalam 'Ulūm Al-Qur'ān”, Jurnal Al-Bayan, Vol 1, No 2 (2016).

${ }^{11}$ Dr. Akhyar Yusuf Lubis, Metodologi Postmodernis, Jakarta: Akademia, 2004, h. 104-105.

${ }^{12}$ Lubis, Metodologi Postmodernis, h. 107
} 
Konsep hermeunetika Dilthey dibangun dengan menolak prinsip a priori dalam kesadaran manusia sebagaimana dipikirakan Immanuel Kant.Dilthey melihat, prinsipprinsip bawaan itu tidak ada.Setiap orang mengada bersama alamnya.Dia menolak konsep diri transenden.Kesadaran itu selalu terkait dengan sosio-historis. Kondisi inilah yang membantu menusia membentuk cara pandang dunia (paradigma, weltanschauung). Prinsip ini meliputi kepercayaan, interaksi dengan lingkungan, konsep nilai, makna hidup, cita-cita dan hukum yang membimbing kehidupan. Karena semua latar belakang pembentuk cara pandang dunia itu perbeda, maka paradigma manusia itu berbeda-beda. Sebab itulah, klaim kebenaran itu tidak berguna.Cara pandang ini yang nantinya menginspirasi postmodernisme untuk meyakini bahwa tidak ada kebenaran absolut, kalaupun ada mustahil dijangkau.Sebab itulah kebenaran diyakini bersifat relatif.

Perbedaan paradigma yang beragam disatukan dengan interaksi dan toleransi.Klaim kebenaran diri itu layak untuk tidak mendapatkan tempat.Bila kebenaran ilmu alam dapat diusahakan untuk ditemukan suatu hukum umum, maka ilmu sosial mustahil.Karena setiap manusia memiliki paradigma yang berbeda.Paradigma itu sangat ditentukan oleh kondisi sosio historis setiap orang.Dalam hal inilah Dilthey menegaskan pentingnya Hermeunetika.Melalui ilmu ini, dapat ditelusiri warisan seseorang melalui teks yang dihasilkannya untuk mengetahui makna sosial dan budaya yang membentuk paradigma pengarang.

Cara tempuh hermeunetika Dilthey adalah bagaimana pengarang mencapai objektivikasi karyanya dan bagaimana prosedur yang dilakukan. Penafsir harus memahami makna parsial sekaligus makna keseluruhan dari teks.Pengarang tentunya telah mereduksi pandangan subjektifnya untuk menghasilkan teks yang merupakan sebuah objketivikasi.Untuk menghasilkan pemehaman yang baik pada sebuah teks, maka perlu ditelusuri dunia subjektif pengarang.Psikologi dan biografi pengarang adalah alat penting dalam konsep hermeunetika Dilthey.

Dalam perkembangan hermeunetika Heidegger mempertanyakan bagaimana menjembatani kesenjangan antara pengalaman subjektif dan pengetahuan objektif.Heideggar juga memberi perhatian kepada tradisi masa lalu, tetapi dia menginkan itu untuk didayagunakan di masa kini.Ketika Dilthey menolak adanya apriori dan Kant mengkaim ketidakmampuan manusia menjangkaunya, maka Heideggar malah menegaskan bahwa di sanalah kunci pengetahuan.Heideggar yakin sesuatu yang dianggap sebagai wilayah yang tidak dapat diketahui itu dapat dijangkan manusia.Buktinya manusia mampu mempertanyakannya.

Heideggar menolak sistem pengetahuan yang memposisiskan manusia sebagai subjek dan alam sebagai objek.Dia melihat manusia dan alamnya adalah satu kesatuan yang tidak bisa diseparasi.Heideggar menolak konsep penentua kebenaran melalui akuratisasi konsep dengan realitas.Menurutnya itu adalah hal mustahil.Bahkan manusia tidak mendapat menjelaskan penghubung antara subjek dengan objek.Sebab itu, bagi Heidegger, kebenaran itu ditentukan melalui meditatif, bukan konfirmatif atau akuratisasia analiais.Kebenaran itu disingkapkan, diciptakan, bukan ditemukan. Inilah 
sang seniman. Mereka menciptakan kebenaran dalam dunianya.Pandangan Heideggar ini semacam mistik, tetapi anti metafisika ${ }^{13}$.

\section{Ricoeur dan Gadamer}

Paul Ricoeur menggabungkan antara filsafat fenomenologi dengan hermeunetika dengan menggabungkan antara pengalaman dan penjelasan.Menurutnya, objek-objek ilmu sosial adalah tindakan yang mengandung makna.Objek ini tidak dapat dibahas melalui ilmu alam tetapu harus melalui hermeunetika karena dia adalam simbol-simbol. Tindakan bermakna itu adalah teks karena ia harus diterjemahkan. Bagi Ricoeur, secara mendasar hermeunetika terbagi menjadi dua yaitu merestorasi makna yang datang kepada pembaca. Kedua adalah hermeunetika kecurigaan yang bertujuan menyingkap ilusi kebohongan dan ilusi kesadaran.

Ricoeur memandang hermeunetika sebagai seni.Selain sebagai ilmu teks, ilmu ini juga dapat diterapkan sebagai ilmu untuk menganalisa tindakan sosial.Dia menjelaskan interpretasi hermeunetika terbagi tiga unsur (1) adanya tanda, simbol, pesan, teks atau tindakan; (2) adanya individu atau kelompok yang ingin tahu tentang makna teks dan; adanya teks ataui simbol sebagai pembawa pesan.Heideggar menegaskan bahwa manusia hadir bersama ruang dan waktunya.Semua itu adalah seperangkat yang harus ditafsirkan.Ricoeur menerapkan ini dalam penafsiran terhadap sastra.Sastra adalah teks yang belum selesai, perlu ditafsirkan.

Bagi pembaca, sebelum membaca sebuah teks mereka memiliki horizon terhadap teks.Horizon ini biasanya dibentuk dengan bacaan atas karya pengerang sebeluimnya, Rpandangan-pandanga orang yang telah membacanya dan pertentangan antara fiksi dan kenyataan. Bagi Ricoeur, teks bukanlah objek yang diteliti. Tekh hanyasebagai sarana untu memahami pesan yang terdapat sie balik teks."Agar penafsiran itu valid, wacana harus dilepaskan dari penulisnya, situasi awal dan penerima atau penafsir awalnya".Tujuannya untu memahami eksistensi manusia.Ricoeur menola bahasa sebagai struktur karena itu memperlakukan bahasa sebagai sistem.Sementara bagi Ricoeur, bahasa adalah wacana, kesatuan antara semiotik (tanda) dan semantik (makna).

Strukturalisme itu mendikhotomi antara language (yang merupakan abstraksi, kode linguistik di tingkat sosial budaya) dengan parole (yang merupakan ujaran bahasa di tingkat individu.Linguistis mengutamakan language, sementara prioritas linguistik adalah parole.Ricoeur menjadikan makna wacana atau linguistik wacana sebagai dasar hermeunetika wacana yang dia bangun. Wacana mengacu pada konteks atau pada dunia di mana dan bagai mana ia dilukiskan, bagaimana diungkapkan dan digambarkan ${ }^{14}$.

Distansiasi, interpretasi dan apropriasi adalah langkah hermeunatika Ricoeur.Melalui distansiasi, hermeunetika Ricoeur tidak bermaksud menemukan makna tersembunyi di balik maksud pengarang.Ricoeur membuka kemungkinan pemaknaan yang beragam.Makna beragam itu bukan untuk mencari mana yang lebih benar tetapi

\footnotetext{
${ }^{13}$ Richard E. Palmer, Hermenetika: Teori Baru Mengenai interpretasi, Cet. II (Yogyakarta: Pustaka Pelajar, 2005), h. 170-171.

${ }^{14}$ Lubis, Metodologi Postmodernis, h. 125
} 
untuk memperluas wawasan tetapi tetap terbuka untuk menentukan mana yang lebih kuat argumentasinya.Apropriasi adalah pengorientasian makna teks kepada pemahaman pembaca dengan berjarak dari maksud pengarang.Percaya, curiga dan transformasi adalah tiga aspek saling berkaitan dalam apropriasi. Hermeunetika kecurigaan tetap dibutuhkan karena pemaknaan tidak pernah sama ${ }^{15}$.

Ricoeur melihat penjelasan dan pemahaman sebagai tesis dan antitesis yang harus disintesakan dan sintesa itu menjadi sebuah tesis baru.Demikian terjadi terus menerus.Penjelasan adalah uraian jajaran proposisi dan makna dan pemahaman adalah menghimpun keseluruhan makna.Penentuan validitas penafsiran adalah dengan probabilitas bukan virifikasi empiris.Suatu penafsiran menjadi lebih probable dengan sistematis dan kekuatan argumentasi. Makna teks adalah sense (isi ideal wacana menurut struktur formalnya) dan reference (gerak transenden ke arah realitas). Hubungan sense dan reference adalah penentu apakah klaim kebenaran itu terpenuhi atau tidak.Kebenaran teks adalah pemenuhan tujuan referensialnya kompleksitas referensial teks adalah dunia teks yang akhirnya diaproriasi pembaca hingga menjadi transformasi kreatif.Apropriasi adalah pertemuan antara dunia teks dengan dunia pembaca.Memahami makna karya adalah mengikuti dinamika karya.

Dalam pemaknaan Gadamer, pertemuan antara teks dengan pembaca disebut pertemuan dua horizon.Gadamer menggunakan fenomenologi Husserl dan eksistensialisme Heidegger.Gadamer monolak kembali ke pengarang dan teks.Peradigma pengarang dan teks berbeda dengan pembaca.Prasangka itu niscaya dalam penafsiran, tetapi tidak boleh menutup kemungkinan munculnya aspek-aspek baru.Tindakan penefsiran itu merupakan tindakan sejarah yang merupakan bagian dari historisitas. Untuk memahami teks harus dilakukan peleburan horizon dengan dialog melalui bahasa. Antara meoden penafsiran harus dileburkan untuk memunculkan makna penafsiran baru.

Bagi Gadamer tugas penafsiran adalah menjembatani kesenjangan antara penulis dengan pembaca.Supaya pembaca dapat merasakan pengalaman penulis.Pembaca perlu berpartisipasi bersama penulis. Persepsi dan kognisi yang mengandung prasangka adalah struktur prapemahaman.Prasangka tidak dapat dihindari sehingga harus diterima dengan ketenangan.

\section{Hermeunetika Alquran \\ Fazlur Rahman}

Terdapat tiga prasyarat memahami Hermeunetika Fazlur Rahman yaitu pendekatan sosio-historis, pendekatan sisntesis-logis dan teori gerak ganda (double movement). Pendekatan sosio-historis mengajak untuk memahami latar belakang turunnya ayat Alquran. Pemahaman latar belakang turunnya ayat harus dibarengi dengan pendekatan sosiologis untuk memahami kondisi sosial pada saat turunnya

\footnotetext{
${ }^{15}$ Akhyar Yusuf Lubis, "Metode Fenomenologi, Hermeneutika dan Penerapannya pada Ilmu Sosial Budaya dan Keagamaan", Materi Kuliah Filsafat Ilmu Pengetahuan \& Metodologi, (Jakarta: Pascasarjana FIB-UI, 2011-2012), hal. 29-37.
} 
Alquran. Dengan pendekatan sosiologis, muncul pemahaman elastisitas penerapan Alquran tanpa menghapus warisan historisnya.Dalam konteks ini dibedakan pemahaman Islam normatif dan Islam historis. Islam normatif adalah sumber norma yang mengatur tata berkehidupan, sifatnya universal. Sementara Islam historis adalah Islam yang diterjemahkan kaum muslim sepanjang sejarah. Meskipun demikian, Islam historis tidak boleh diabaikan karena sangat membantu penerapan islam normatif dalam konteksnya.

Biasaya Rahman menggunakan pendekatan sosio-historis dalam memahami ayatayat hukum.Sementara pendekatan sintesisis-logis digunakan untuk memahami ayatayat tentang metafisika atau ayat-ayat teologis.

Ayat-ayat dalam Alquran tidak bisa dipahami secara atomistik. Antara satu ayat dengan ayat yang lain salng berhubungan. Pemahaman seperti ini dapat memberikan pemahaman yang sistematis dan kontekstualis untuk menghasilkan pemaknaan yang tidak atomistik, tidak literalis dan tidak tekstualis untuk mendapatkan pemaknaan yang mampu merespon problematika kekinian.Yang dimaksud double movement (gerak ganda) dalam sistem hermeunetika Rahman adalah melihat Alquran dari masa sekarang ke masa Alquran turun lalu kembali lagi ke masa kini. Kepentingan sistem ini karena Rahman memahami bahwa pada masa turunnya Alquran mengalami proses dialektika dengan realitasnya baik dalam bentuk menerima dan melanjutkan (tahmil), melarangnya (tahrim), dan menerima dengan merekonstruksinya (taghiyyur).

Gerak pertama adalah menelusuri konteks turunnya ayat spesifik yang merupakan respon atas peristiwa spesifik dengan menemumkan pesan umum dari ayat spesifik.Setelah pesan umum itu ditemukan, maka pesan umum tersebut dikontekstualisasikan pada problem kontemporer yang spesifik.Untuk itu diperlukan analisa yang cermat atas problematika kontemporer sehingga dapat dinilai dan diubah sejauh yang dibutuhkan.Diperlukan pula prioritas-prioritas baru agar dapat diimplementasikan nilai-nilai Alquran secara baru ${ }^{16}$.

Dengan penerapan pendekatan ini, dapat dilihat bagaimana kegagalan kontekstualisasi Alquran untuk masa kini terjadi karena kegagalan metodologis.Dengan kemampuan penerapan hermeunetika Rahman ini, maka diharapkan dapat menjadikan Alquran sebagai rujukan efektif dalam mengatasi problematika kontemporer.Rahman mengharapkan Alquran dapat dijadikan sebagai landasan nilai dalam penerapan masyarakat yang adil.Rahman yakin setiap kebutuhan manusia untuk kemaslahatan tidak bententangan dan memiliki prinsip dukungan dari Alquran.

\section{Khaled Abou El-Fadl}

Dalam hermeunetita terdapat tiga fariabel yaitu pengarang, teks dan pembaca.Dalam konteks hermeunetika Alquran, pengarang berati Allah, teks berarti Alquran dan pembaca adalah umat manusia.Sebagai pengarang, Tuhan menempatkan teks dalam alur interpretasi, tetapi tidak menentukan maknanyam sehingga pemahaman

\footnotetext{
${ }^{16}$ Rifki Ahda Sumantri, "Hermeunetika Al-Quran Fazlur Rahman: Metode Tafsir Double Movement" Komunika: Jurnal Dakwah dan Komunikasi, Vol 7 No.1, 2013.
} 
penbaca ditentukan dengan pemahaman atas teks sebagai sombol.Teks, tidak boleh digunakan tanpa batas.Karena ada kaidah untuk menentukan makna.Tetapi harus diingat bahwa teks tidak mampu menampung seluruh maksud Tuhan.Teks hanya mampu menampung petunjuk kehendak Tuhanm teks juga bergantung pada konteks zamannya.Pembaca, sangat menentukan makna dengan asumsinya.Ini tidak bisa dihindarkan.Sisten konsumsi informasi oleh akal manusia memang bersifat dialektis.Sehingga persepsi subjek adalah penentu pemahaman teks.Skema dialektika ini juga dapat digambarkan dalam hermeunetika el-Fadl sebagai penentu teks.Maksudnya, dialektika antara pengarang, teks dan pembaca itulah yang menetukan makna ${ }^{17}$.

Sebuah makna itu bersifat dinamis.Pengarang sebabagi tesis, teks sebagai antitesis dan pembaca sebagai sintesis yang menentukan makna.Pemaknaan pengarang itu bersifat subjektif, sehingga selalu terbuka peluang untuk pemaknaan yang baru.El-Fadl menerapkan sistem interpretasi dinamis dengan menggali konteks kekinian dari makna sebuah teks untuk menemukan dampak dan kedudukan makna awal teks. Tidak hanya memahami makna awalnya, sebuah teks juga harus ditemukan makna dalam konteks kekinian.Sehingga dalam menemukan makna teks terdapat dua tugas di sini yaitu menemukan makna dasarnya menemukan makna kontekstualnya.

Pembaca harus dapat membayangkan makna yang dikehendaki teks pada masa lalu jika ia diterapkan pada masa kini. Sehingga teks tidak hanya sesuai dengan konteks masa lalu tetapi juga dapat diterapkan di masa kini.Sebagai teks masa lalu yang diperuntukkan bagi masa kini eliFadl memperkenankan konsep 'saling menganal' (litaarrufu).Konsep ini dimaksud sebagai saling membantu sebagai pendukung untuk saling mengenal.

Problem yang dihadapi dalam kontekstualisasi Alquran untuk masa kini adalah penafsiran yang berorientasi kepentingan aliran dan kelompok tertentu.Alquran diklaim harus hanya menjadi otoritas pihak tertentu. Untuk menghindari masalah ini, el-Fadl menawarkan lima persyaratan pembacaan Alquran. Pertama, kejujuran pembaca.Pembaca atau penefsir harus menjelaskan asumsi dasar yang dimiliki dalam memaknai Alquran.Karena asumsi dasar ini sangat menentukan terbentuknya makna.Kedua, ketekunan dan ketulusan.Pembaca harus mengerahkan segala kemapuan dan keikhlasannya dalam memahami dan menemukan petunjuk-petunjuk relevan dari Alquran.Ketiga mempertimbangkan segala aspek.Segala aspek yang terkait dengan historitas teks dan segala aspek terkait kontekstualitas teks harus dapat dianalisa dan diterapkan untuk kontekstualisasi Alquran.Keempat rasionalitas.Pembaca atau penafsir harus mampu menganalisis teks secara rasional.Analisa ini harus dilakukan secara sistematis agar tidak keluar dari konteksnya.Kelima adalah pengendalian diri.Pembaca atau penafsir harus memahami batasibatas kemampuan dan batas-batas kewenangan diri.Jangan juga hasil penafsirannya sengaja membuka peluan untuk dimanfaatkan untuk kepentingan kelompok tertentu ${ }^{18}$.

\footnotetext{
${ }^{17}$ Khaled Abou El-Fadl, Atas Nama Tuhan, (Jakarta: Serambi, 2004), h. 178-179.

${ }^{18}$ Abou El-Fadl, Atas Nama Tuhan, h. 181.
} 


\section{Mohammad Arkoun}

Probelm disintegrasi Alquran dengan konteks sosial kontemporer adalah estimasi bahwa Alquran adalah ungkapan misteri yang transenden.Dalam masa krisis moral dan situasi yang tak menentu, Alquran turun untuk mentransendensikan manusia tanpa bantuan perangkat apapun untuk memahami teks transenden itu.Akibatnya Alquran dikristalkan sebagai teks yang tak tersentuh oleh realitas sosial dalam konteks tertentu.Untuk itu, usaha pertama Mohammad Arkoun adalah melakukan dekonstruksi atas sakralisasi Alquran.Dengan dekonstruksi ini, kesalahan, disorientasi dan penyimpangan dalam Alquran dapat teratasi.

Akoun mengatakan bahwa Alquran itu terbagi tiga.Pertama adalah Ummul Kitab yang tempatnya berada di Lawh Mahfudz.Dia tidak dapat dipahami manusa.Ummul Kitab bersifat kekal dan abadi.Kedua adalah Alquran yang kita kenal hari ini.Kedua adalah Alquran yang diturunkan kepada Nabi Muhammad.Ketiga ini adalah Alquran yang dikodifikasi, kita baca dan dapat kita pahami.Sifatnya tidak tetap.Ditujukan kepada manusi unruk semua zaman di segala tempat.Untuk diterapkan pada segala konteks kehidupan.Sebab itu yang keduai ini, ketika telah mengalami sakralisasi, harus didekonstruksi supaya dapat berdaya guna bagi kontek sosial kekinian ${ }^{19}$.

Arkoun mengatakan Alquran pada tahan kedua itu lebih suci, lebih terbuka dan lebih mudah dipahami.Alquran ketika masih sebagai lisan masih sangat autentik.Sementara Alquran pada periode ketiga menjadi dogma yang disakralkan. Menurut Arkoun, Hanya Alquran di Lawah Mahfudz yang benar, sementara Alquran lisan telah musnah dan tak akan kembali. Untuk itu, satu-satunya cara yang dimiliki adalah mendekonstruksi tek Alquran supaya dapat ditemukan semangat orisinil dari Alquran dan didayagunakan dalam kehidupan kekinian.

Dalam pandangan Arkoun.Tafsir Alquran telah mereduksi sedemikian rupa teks Alquran hingga tafsir itu benar-benar telah menghalangi untuk memahami Aquran. Misalnya penafsiran pada cerita -cerita israiliyat dengan mengelaborasikan motologimitologi, tafsir-tafsi perpektif teologi yang menumpang pada logika aristotelian dan pencocok-cocokan pememuan sains dengan Alquran. Semua itu harus disingkiran dalam memahami Alquran sehingga Alquran dapat kembali hadir sebagai sebuah teks dengan cara yang normal: adanya seorang pembaca yang sedang berinteraksi dengan teks. Teks Alquran harus kembali difungsikan sebagai diskursus linguistik.

Arkoun mengatakan setiap teks Alquran mewakili tiga langkah.Pertama adalah Allah mengirimpan sebuah pesan kepada Muhammad untuk disampaikan kepada ummat manusia.Kedua, manusia terbagi menjadi yang beriman dan yang tidak beriman.Yang beriman adalah yang menerima dan menjalankan Alquran dalam kehidupan.Yang menolak adalah yang tidak mempercayai dan tidak mengamalkan isi Alquran.Ketiga adalah hari pengadilan yaitu masa ketika yang menerima dan

\footnotetext{
${ }^{19}$ Bambang Sugiharto, Postmodernisme Tantangan Bagi Filsafat, Yogyakarta: Kanisius, 1996, h. 4348.
} 
mengamalkan Alquran mendapatkan keselamatan dan yang menginkarinya mendapatkan ganjaran ${ }^{20}$.

Dalam pandangan Arkoun, kata-kata Tuhan harus dilihat sebagai simbol yang terbuka bagi munculnya makna bagi setiap pembaca.Karena teks Alquran dilihat sebagai simbol, maka Arkoun menyuguhkan teknik analisa semiotik untuk memahami Alquran. Arkoun menyusun langkah-langkah analisa semiotik sebagai berikut: (1) Proses linguistis, yaitu proses pengajaran dalam teks Alquran mencakup data-data linguistik, bentuk determinan, jenis kata, sintaksis, persajakan. Ini untuk mengetahui aktan-aktan (pelaku-pelaku) tindakan yang ada di dalam teks; (2) Analisis hubungan kritis ujaran-ujaran dalam teks, analisa linguisis dilanjutkan dengan mencari hubunganhubungan antara satu tanda dengan tanda yang lain berdasarkan subjektivitas yang immanen dalam teks dengan melibatkan karya-karya terdahulu tentang definisi-definisi sistem bahasa Arab; (3) Pembacaan historis; untuk mengenal simbol-simbol linguistis, keagamaann budaya yang telah dipakai daam pemaknaan; (4) Pembacaan Antropologis; untuk mempertanyakan apakah diluar dogma dan budaya teks mengandung rujukan asalimuasal? Lalu apa kekhasan dogma dan budaya itu sehubungan dengan teks? Ini dipertanyakan untuk menemukan petanda transenden untuk menunjukkan bagaimana bahasa dipakai dalam berbagai simbol ${ }^{21}$.

Langkah itu semua untuk memecah absolutisasi pemahaman atas Alquran sehingga dapat dikembalikan menjadi simbol untuk ditemukan maknanya.

\section{Nasir Hamid Abu Zayd}

Ketika Alquran diturunkan kepada manusia, maka butuh suatu penyesuaian dengan pemahaman manusia.Dalam hal ini Alquran berubah dari tanzih menjadi takwil. Abu Zayd meyakini kekuasaan telah memberi peran sangat besar dalam membentuk pemahaman terhadap nash. Transformasi besar terjadi ketika teks Alquran dijadikan mushaf¥ menurut Abu Zayd, pengkodifikasian Alquran menyebabkan Alquran yang mengandung makna menjadi hampa makna.Sehingga Abu Zayd menegaskan bahwa Alquran adalah teks linguistik dan produk budaya yang berangkat dari dan oleh realitas ${ }^{22}$.

Dengan alasan tersebut, Abu Zayd mengatakan bahwa Alquran adalah kitab sastra Arab terbesar.Dia memposisikan Alquran setara dengan kaarya-karya sasta yang digubah para penyair.Alquran dimaksai sebagai sebuah karya yang merefleksikan abstraksi sosio-antropologis.Dengan pemaknaan ini, Abu Zayd ingin menegaskan bahwa penerapan hukum tetap yang menyandarkan diri pada Alquran adalah tidak tepat.Alquran sebagai sebuah teks historis, warisan kebudayaan tidak memerlukan metode khusus untuk dipelajari karena itu dapat mencegah pemahaman atas teks-teks agama secara mandiri.Ini menyebabkan Alquran tidak dapat dikontekstualisasikan pada

\footnotetext{
${ }^{20}$ Nasrudi, "Manhaj Tafsir Mohammad Arkoun”, Maghza: Jurnal IlmuAlquran dan Tafsir, Vol. 1, No. 1, Januari-Juni 2016. h. 86-92

${ }^{21}$ Nasrudi, "Manhaj Tafsir...", h. 86-92.

${ }^{22}$ Fahmi Salim, Kritik Terhadap Studi Alquran Kaum Liberal, Jakarta: Perspektif, 2010, h. 298.
} 
setiap waktu dan kondisi yang berbeda.Sakralisasi teks menyebabkan teks menjadi nirakses dan disfungsi.Sebab itulah, aturan-aturan tentang metode tafsir harus dihapuskan agar Alquran dapat diakses.Metode tafsir adalah penghalang akses Alquran.

Abu Zayd melihat nash Alquran itu sendiri adalah produk budaya masa lalu. Kepada teks telah dijadikan sesuatu semacam benda sakral.Sakralisasi itu menutup akses untuk memahami Alquran.Untuk itu, segala macam bentuk sakralisasi harus disingkirkan dengan memaknai Alquran secara esoterik.Karena aspek eksoterinya bisa membuang bias-bias sakralitas atas teks.Abu Zayd melihat, belakangan ini kita membaca teks Alquran dengan teks yang telah dibingkai dengan asumsi hukum dan teologi sehingga tidak dapat didayagunakan sebagai teks sosiologis kontekstual.Untuk itu, Abu Zayd mengajak untuk jujur mengakui bahwa teks Alquran.Telah menjadi sebuah teks sastra.Sehingga dapat diperlakukan sesuai dengan statusnya sebagai teks sastra.Dengan demikian, teks tersebut dapat didekati secara hermeunetis.

Abu Zayd menuduh teks Alquran selama ini telah mengalami ideologisasi yang diciptakan oleh kelompok tertentu.Usaha Abu Zayd adalah mengembalikan Alquran ke dalam posisi yang sebenarnya yakni sebuah teks sastra.Sehingga Alquran dapat didekati dengan pendekatan kajian bahasa.Ideologisasi dan mitologisasi Alquran harus dihapuskan karena sebenarnya tidak sesuai dengan semangat Alquran itu sendiri.

\section{Penutup}

Hermeunetika Alquran yang dibahas kaum Muslim semuanya tidak lepas dari inspirasi dan gagasan yang disumbangkan oleh para pemikir hermeunetika Barat mulai dari Sheiermacher hingga Gadamer.Orientasi pertama lahirnya ilmu hermeunetika di Barat adalah kritik dan rekonstruksi terhadap kitab suci. Orientasi ini dianggap relevan oleh para pemikir muslim untuk dijadikan metode untuk merekonstruksi pemahaman terhadap Alquran.

Hermeunetika Barat memiliki fondasi epistemologis yang kuat sehingga wajar sangat mempengaruhi para pemikir Muslim.Khususnya terhadap tinjauan historitas Alquran yang menjadi kendala utama sulitnya mengakses makna dari Alquran.Semua pemikir hermeunetika Muslim menekankan pada kajian historitas ayat agar mampu meletakkan persoalan historis dari konteks turunnya Alquran dan kontekstualisasi nilainilai Alquran dalam kehidupan kekinian.

Para pemikir muslim merasa resah dengan pengorientasian makna Alquran oleh kelompok-kelompok tertentu untuk kepentingan aliran kelompoknya. Mereka mengunci makna Alquran sehingga menjadi tidak dapat dikontekstualisasikan dengan nilai-nilai kekinian. Akibatnya kaum muslim menjadi kesulitan mengakses Alquran untuk dijadikan rujukan dalam mengatasi persoalan beragam yang mereka hadapi. Untuk itulah ara pemikir muslim menawarkan hermeunetika sebagai solusi agar kaum muslim dapat menjadikan Alquran sebagai pedoman kehidupan di manapun dan kapanpun mereka berada. 


\section{DAFTAR PUSTAKA}

El-Fadl, Khaled Abou Atas Nama Tuhan, Jakarta: Serambi, 2004.

Eliade, Mircea The Encyclopedia of Religion, Vol. 9, New York: Macmillan Library Reference USA, 1995.

Florio, Joanna and Dilys Parkinson, Oxford Advanced Learner Dictonary, Oxford: Oxford University Press, 2000.

Gardner, James, Encyclopedia of Faith and Religions of the World, Vol. III, New Delhi: Aryan Books Inernational, 1999.

Husaini, Adian dan Abdurrahman al- Baghdadi, Hermeneutika \& Tafsir Al Quran, Jakarta: Gema Isani Press, 2007.

Lubis, Akhyar Yusuf Dekonstruksi Epistemologi Modern, Jakarta: Pustaka Indonesia Satu, 2006.

Lubis, Akhyar Yusuf Metodologi Postmodernis, Jakarta: Akademia, 2004 Richard E. Palmer, Hermenetika: Teori Baru Mengenai interpretasi, Cet. II Yogyakarta: Pustaka Pelajar, 2005,

Lubis, Akhyar Yusuf, "Metode Fenomenologi, Hermeneutika dan Penerapannya pada Ilmu Sosial - Budaya dan Keagamaan", Materi Kuliah Filsafat Ilmu Pengetahuan \& Metodologi, Jakarta: Pascasarjana FIB-UI, 2011-2012.

Muliono, R., Slamet, "Hermeneutika Al-Qur'an: Antara Pemaknaan Tekstual Dan Kontekstual" Ulumuna, Volume XIV Nomor 1, 2010.

Nasrudi, "Manhaj Tafsir Mohammad Arkoun", Maghza: Jurnal IlmuAlquran dan Tafsir, Vol. 1, No. 1, Januari-Juni 2016.

Salim, Fahmi, Kritik Terhadap Studi Alquran Kaum Liberal, Jakarta: Perspektif, 2010.

Salim, Peter The Contemporary English-Indonesia Dictonary, Jakarta: Modern English Press, 1985.

Shalahuddin, Henri, Al-Qur'an Dihujat, Cet. II Jakarta: Al-Qalam, 2007.

Sugiharto, Bambang, Postmodernisme Tantangan Bagi Filsafat, Yogyakarta: Kanisius, 1996.

Sukron, 'Mokhamad Kajian Hermeneutika Dalam 'Ulūm Al-Qur'ān”, Jurnal Al-Bayan, Vol 1, No 22016.

Sumantri, Rifki Ahda "Hermeunetika Al-Quran Fazlur Rahman: Metode Tafsir Double Movement" Komunika: Jurnal Dakwah dan Komunikasi, Vol 7 No.1, 2013.

Wijaya, Aksin" Hermeneutika Al-Qur'an: Memburu Pesan Manusiawi Dalam Al-Qur'an”, Ulumuna, Volume XV Nomor 2 Desember 2011. 